\title{
Times are a changing for the IUJ
}

\author{
Peter Dwyer $^{1} \cdot$ Paul Riss ${ }^{2}$
}

Received: 28 February 2016 / Accepted: 28 February 2016 / Published online: 6 April 2016

(C) The International Urogynecological Association 2016

The International Urogynecology Journal (IUJ) functions through the generosity, hard work, and good will of the authors who submit their research for scrutiny and publication and the reviewers who evaluate this work and help the editors in the editorial process leading to publication. The IUJ is a monthly publication with 12 issues a year and more than 2000 pages. More than 650 manuscripts are submitted, with approximately 300 manuscripts being accepted and published. More than 3000 reviewers are invited and 2000 reviews completed. The average reviewer takes 10 days to complete the review and does 3.6 reviews a year. Every review is assessed and graded by the editor before she or he makes the final decision. Many reviews are performed by members of the editorial board who are experienced clinicians and give their time and good name to the journal. There is also the Springer production team of editors, editorial assistants, and production managers. So many people are involved in the production of the final manuscript and the monthly issue of the IUJ.

\section{Paul Riss}

paul.riss@gmail.com

Peter Dwyer

peter@pldwyer.com

1 Department of Obstetrics and Gynaecology, Mercy Hospital for Women, University of Melbourne, Melbourne, Australia

2 Department of Obstetrics and Gynecology, Medical University Vienna, Vienna, Austria
Renewal and reinvigoration is essential for any successful organization, and the IUJ is no exception. Bringing in new reviewers, editorial board members, and editors is just as important as having experienced older heads to balance the editorial ship. For this reason, we have made changes to the editorial board and the group of editors. We welcome on board our new editorial board members who come from all parts of the world, and we have appointed as new editors Rufus Cartwright (UK), Karl Tamussino (Austria), and Gin-Den Chen (Taiwan).

We would like to thank retiring board members for their excellent contribution. A special thanks to Chris Maher for his time and efforts as editor over the last few years. He has given excellent service and will continue on the board.

Finally, the IUJ will appoint a new editor(s) in chief to replace us. We have served as editors and then editors in chief from 2011 to 2016 and have enjoyed the role very much, even with its many challenges. This duty has been made so much easier and enjoyable with the help of the Springer publishing team, our fellow editors, and our many colleagues who helped in the reviewing process. Also, the board of the International Urogynecology Association (IUGA) - the owners of the IUJ-have been extremely supportive of the journal and its editorial team. Advertisements for the position of editor in chief will be circulated in the next few months and a final decision made at the Annual Scientific Meeting of IUGA in Cape Town, South Africa. The new editor(s) in chief will start in 2017.

The IUJ has a bright future. 